\title{
PAULO FREIRE E O AGORA
}

\author{
Francisco Thiago Cavalcanti da Silva ${ }^{1}$ \\ Maria Vitória Mamede Maia ${ }^{2}$
}

\begin{abstract}
RESUMO
Neste breve ensaio, o discente do programa de pós-graduação sticto-sensu em Educação pela Universidade Federal do Rio de Janeiro, Francisco Thiago Cavalcanti, discorre sobre a importância de Paulo Freire para a educação em tempos de escassa ética na politica. Como renovar nossos votos em uma educação crítica, emancipadora, democrática? Por que é interessante para o governo atual que as camadas populares não tenham acesso ao conhecimento? Por que Paulo Freire se faz tão necessário para a atual conjectura de nosso país?
\end{abstract}

Palavras-chave: Paulo Freire. Educação popular. Escola Família Agrícola.

\section{RESUMEN}

En este breve ensayo, el estudiante del programa de posgrado sticto-sensu en Educación de la Universidad Federal de Río de Janeiro, Francisco Thiago Cavalcanti, analiza la importancia de Paulo Freire para la educación en tiempos de poca ética en la política. ¿Cómo podemos renovar nuestros votos en una educación crítica, emancipadora y democrática? ¿Por qué es interesante para el gobierno actual que los estratos populares no tengan acceso al conocimiento? ¿Por qué es Paulo Freire tan necesario para la conjetura actual de nuestro país?

Palabra clave: Paulo Freire. Educación popular. Escola Família Agrícola.

\begin{abstract}
In this brief essay, the student of the sticto-sensu postgraduate program in Education at the Federal University of Rio de Janeiro, Francisco Thiago Cavalcanti, discusses the importance of Paulo Freire for education in times of little ethics in politics. How can we renew our vows in a critical, emancipatory, democratic education? Why is it interesting for the current government that the popular strata do not have access to knowledge? Why is Paulo Freire so necessary for the current conjecture of our country?
\end{abstract}

Keyword: Paulo Freire. Popular education. Escola Família Agrícola.

\footnotetext{
${ }^{1}$ Mestrando em Educação (UFRJ).

${ }^{2}$ Professora Associada (UFRJ); Doutora em Educação (PUC-RJ e Professora do PPGE (UFRJ).
} 
1.

Sou Francisco Thiago, discente do programa de pós-graduação stricto-sensu em Educação da Universidade Federal do Rio de janeiro. No segundo semestre de 2019, foi ofertada a disciplina obrigatória Educação Brasileira, ministrada pela professora Libânia Nacif Xavier, em colaboração com a professora Ana Magaldi. Logo no início das aulas as professoras propuseram como método avaliativo, a divisão da turma em grupos de acordo com as afinidades temáticas das pesquisas desenvolvidas pelos alunos. O trabalho final consistia em apresentarmos em sala um seminário acerca do tema do grupo e a produção de um ensaio individual (este que vos apresento, agora revisado por minha orientadora Maria Vitória Mamede Maia) a ser entregue às professoras. Fiquei no grupo “educação e os movimentos sociais". Meu projeto pessoal no mestrado, entre outras coisas, disserta sobre a educação no contexto do campo, da juventude rural. Portanto, dividi o trabalho com as discentes Rafaella e Rosana, que também investigam a educação no contexto dos movimentos sociais. Meu recorte no seminário, apresentado em sala, foi sobre como conheci a Escola Família Agrícola durante minha graduação em Dança, pela Universidade Federal de Viçosa, em Minas Gerais, e por que esse tema me atraiu de volta à academia quase dez anos depois de formado. Outro principal eixo que aproximou o meu grupo de trabalho foi Paulo Freire, sua importância para a educação brasileira e as camadas populares. Paulo Freire é o principal representante da educação popular no Brasil, inclusive, seu projeto de educação é exemplo em vários lugares do mundo. Nestas poucas páginas relaciono a Escola Família Agrícola com os ensinamentos do pedagogo, levanto o debate sobre a educação e a política atual de nosso país e reitero o desejo urgente de mudança tão esperada por grande parcela da população denominada erroneamente "minoria", visto que os oprimidos, excluídos e miseráveis ainda são em maior número.

2.

Em 2009, através da Universidade Federal de Viçosa, em Minas Gerais, onde cursei o Bacharelado em Dança, tive a oportunidade de participar do XII EIV (Estágio Interdisciplinar de Vivência) Regional. O EIV é um programa de formação política que sensibiliza para as questões agrárias, sindicais, econômicas, sociais e ambientais, com todos os seus desdobramentos. Após o processo teórico, que durou cerca de um ano, com professores, líderes sindicais e de movimentos sociais, como o MST, moradores de áreas rurais, entre outros, vivi a experiência prática que consistiu em morar por um mês na casa da agricultora Cristina Moura, uma das articuladoras do Sindicato dos Trabalhadores Rurais do município de Acaiaca, também 
em Minas Gerais. Junto à família de Cristina acompanhei a rotina da vida no campo, plantei, colhi, fiz ações do Sindicato, como distribuir informativos nas casas dos moradores do município e aplicar questionários sobre sustentabilidade e agroecologia, cuidei das crianças, acompanhei algumas aulas na Escola Família Agrícola e participei das festividades. A partir desse acontecimento, que transformou e ampliou minha visão de mundo, surgiu o desejo de continuar contribuindo com o desenvolvimento local, junto a essa comunidade rural.

Onze anos se passaram desde que vivi essa experiência, mas o desejo de voltar a esse lugar, a essa realidade, foi pulsando dentro de mim durante todo esse tempo. Formado em dança, tive a oportunidade de trabalhar em muitos países, continentes, conhecer diversas culturas. Fora do Brasil, a arte tem outro valor, os artistas são reconhecidos, respeitados, subsidiados.

No Brasil, em 2013, vivemos o golpe que depôs a então presidenta da república Dilma Roussef. De lá pra cá, aconteceram muitas perdas para a democracia e para as conquistas das camadas populares junto ao governo de esquerda. A educação perdeu, a cultura perdeu, os movimentos das minorias perderam. Muito. Diante desse quadro, quis muito voltar a estudar, precisava entender mais sobre direitos humanos, educação, cidadania, cultura, história, soberania, filosofia. Queria aprender mais para ensinar, e por isso entrei para a pós da Educação. Meu principal objetivo é desenvolver um projeto que envolva arte, afeto, crescimento intelectual, emancipação. A experiência em Acaiaca em 2009 me fez querer voltar para lá agora em 2020, para que eu possa contribuir minimamente com aquela comunidade. Se está difícil nos grandes centros, nas pequenas cidades está muito pior.

Pude perceber que, em Acaiaca, pouco se ouviu falar em Arte, construção poética, subjetiva. A realidade é dura, o modo de vida é precário. Os jovens são acomodados por encararem a existência como determinista. Muitos deles desejam migrar para os centros urbanos por estarem insatisfeitos com a vida no campo. A mídia televisiva é um elemento constante nos lares da comunidade e o acesso à internet é limitado. Na cidade não há museus ou bibliotecas. O conhecimento e a informação assim tornam-se escassos e alienantes. No artigo "Um marco reflexivo para a inserção social da juventude rural”, Stropasolas $(2007$, p.284) faz o seguinte comentário:

Vivemos uma época de alargamento do mundo cultural. E isto se reflete no imaginário e nas demandas da juventude. Esta ampliação do universo simbólico e valorativo é percebido nos depoimentos dos jovens que desejam o melhor dos dois mundos, o rural e o urbano, uma síntese muito difícil de conseguir. [...] Mas a busca desta conflituosa unidade sociocultural como desejo, como demanda, vem sendo explicitada de forma grecorrente nas trajetórias e nos projetos de vida de moças e rapazes de origem rural e residentes nas pequenas localidades. A inclusão digital e o acesso à informação e à comunicação interpessoal, cada vez mais demandados por esses jovens, tendo em vista a interação criada pelos jovens que passam a ter acesso à Internet nas escolas, no sindicato, na igreja etc. muda a maneira de estar no mundo porque muda o tamanho do mundo. 
A informação pluraliza o conhecimento. Para os jovens de Acaiaca é frustrante não poder acompanhar o desenvolvimento tecnológico, não poder usufruir dele. Essa impossibilidade gera a insatisfação de se viver em um lugar afastado das novas mídias que democratizam o saber. A inacessibilidade a esses bens de consumo faz com que os jovens se sintam atores inferiores na sociedade.

O Brasil é um país grande que possui muitas idiossincrasias, riquezas naturais, culturais, materiais, simbólicas e uma desigualdade social tão grande quanto seu espaço geográfico. Morando cinco anos no interior de Minas Gerais pude perceber quantas cidades periféricas e famílias são esquecidas e negligenciadas pelo governo e pelas ações públicas. Agora posso presenciar esse descaso diariamente, pois moro em uma comunidade no Rio de Janeiro, antes pacificada pela UPP e agora, novamente tomada por uma facção violenta, além disso trabalhei sete anos na Maré, o maior complexo de favelas do Rio.

Para essa população marginalizada que é a maioria em nosso vasto território brasileiro, é necessário pensar políticas que incluam, estimulem o conhecimento, a conscientização de ser e estar no mundo, a noção básica e integral de direitos e deveres de cada um. Óbvio que o poder hegemônico não quer que a população se abasteça de saber, pois a população se instruindo, adquirir-se-ia o discernimento de votar em bons representantes, por exemplo. Também não se sujeitaria a ser coadjuvante de sua própria vida, servindo aos poderosos. É preciso devolver à população rural do Brasil, seu valor, buscar o resgate e a valoração da história, da identidade e da memória desses moradores, conscientizando-lhes como sujeitos-atores de suas existências.

Paulo Freire foi um educador brasileiro que defendeu com unhas e dentes as classes oprimidas; atualmente, no governo bolsonarista, é execrado pelo presidente e seus aliados. Para entender o motivo dessa censura e depreciação a obra de Freire, basta folhear alguns de seus livros como: Pedagogia do Oprimido, Pedagogia da Autonomia, Educação como prática de liberdade, Extensão ou comunicação?, entre outros. O autor defendeu ao longo de sua vida, a educação como pilar essencial de uma sociedade harmônica e livre. Para Freire, o educador democrático consciente de seu papel deve entender que a educação por si só não pode revolucionar uma sociedade, mas ela não é uma faculdade neutra, ela é um potente agente de transformação e mudança. A verdadeira educação não serve à ideologia dominante e sim a uma política-pedagógica que questiona o paradigma em que vivemos. Para FRIGOTTO (2017, p.96):

A importância de Paulo Freire no cenário educacional brasileiro merece, inclusive, destaque, na direção contrária do que vem sendo ressaltado de forma reiterada e estereotipada pelo movimento Escola sem Partido, que o apresenta como referência nociva a ser "varrida" das escolas. Ao dialogarmos com nosso passado educacional, podemos perceber que esse educador teve justamente sua trajetória marcada pela defesa incansável da escola pública e pelo compromisso com práticas que valorizam os educandos como sujeitos ativos em seu processo formativo [...]. Essa tradição 
democrática, reforçada no processo de redemocratização do país na década de 1980 e de crítica à ditadura civil-militar e a seus impactos na cena educacional, vem estimulando, não uma doutrinação "de esquerda", como tentam fazer crer indivíduos totalmente distanciados do "chão da escola", mas uma educação pautada pela autonomia, liberdade e pelo pensamento crítico.

O Movimento Escola sem Partido, citado por Frigotto, é um exemplo de como a elite está encarando o projeto de educação brasileira. Esse movimento foi criado pelo advogado Miguel Nagib em 2004; mais tarde, inspirou vários políticos a adotarem projetos de lei a favor de uma escola sem partido. Consiste, grosso modo, em um modelo onde os profissionais da educação se isentam de qualquer posicionamento crítico diante dos conteúdos escolares.

À revelia do projeto de governo fascista que abala as estruturas sociais, políticas e econômicas de nosso país, existe, citada acima, a Escola Família Agrícola, que tem como uma das linhas-força de pensamento, a pedagogia de Paulo Freire, que ao contrário da ideologia de Nagib, acredita na autonomia do sujeito através da prática de criticidade.

A Escola Família Agrícola é um modelo de escola que existe em algumas cidades do interior do Brasil. Sua fundação se deu em 1935, no interior da França, ligada à igreja católica. No Brasil a primeira experiência com esse modelo foi em 1968 no Espírito Santo. A EFA, é uma espécie de internato rural, que adota a pedagogia da alternância como um dos pilares primordiais. O público é majoritariamente jovem, com idades variadas entre 15 e 25 anos. Os alunos ficam quinze dias na escola e quinze dias em casa. Além dos conteúdos do currículo formal de ensino, os jovens aprendem sobre temas vinculados à realidade do campo, capacitando-os a usufruir da melhor maneira o espaço que habitam. Um dos principais objetivos da Escola Família Agrícola é valorizar o sujeito do campo, buscando estimular em seus alunos a consciência, a autonomia, a autocrítica, evitando também a evasão da juventude para as grandes cidades.

Se a educação nos grandes centros do país sofre há anos a desvalorização e o desmantelamento por parte das autoridades públicas, o que haveríamos de pensar em relação a educação no interior de nossos brasis? O que se vê, quem por acaso se interessa, é que os movimentos sociais são fortes e seguem resistindo. Os movimentos se mobilizam em pequenas sociedades e lutam para que os direitos humanos sejam de todos e não somente dos privilegiados. A Escola Família Agrícola, procura assegurar que a juventude rural é necessária e capaz de adquirir conhecimento, saúde, lazer, trabalho. É o básico. A educação é a base. Como afirma FRIGOTTO (2017, p.99):

A escola é o lugar importante no processo de subjetivação de crianças e jovens de diversos segmentos socioeconômicos do país. Na instituição escolar, esses sujeitos têm a possibilidade não apenas de aprender conteúdos novos, mas também de expandir suas visões de mundo, por meio do convívio com colegas e docentes que 
possuem diferentes pontos de vista e com quem compartilham um espaço comum, e de constituir-se afetiva e politicamente a partir dessa experiência.

Em tempos de intolerância e desvalorização da matéria humana, precisamos dar voz às classes mais excluídas de nossa sociedade, entender como podemos colaborar uns com os outros sem que a relação opressores x oprimidos continue a existir. Grande parte da alimentação que consumimos na cidade grande, vem do trabalho camponês. Não podemos esquecer que essa colaboração deveria ser mútua e não parasitária. Não podemos ser coniventes com essa escravidão dissimulada da contemporaneidade. Para isso, não esquecer que a educação pode e dever ser uma prática de liberdade. E parafraseando Freire: ninguém liberta ninguém. As pessoas se libertam em comunhão.

\section{3.}

Enquanto os governadores do Brasil destroem tudo o que foi construído por anos de luta em nossa democracia, autoridades internacionais reconhecem Paulo Freire como um dos principais intelectuais e influenciadores da educação moderna e contemporânea. Brecht perguntava-se que tempos são esses em que temos que falar o óbvio. Eu quis falar sobre o óbvio em minha pesquisa de mestrado por que o que o poder hegemônico imperialista faz com as cabeças das pessoas é muito perigoso, desarticula, empobrece. Estamos vivenciando um governo que enaltece a alienação, a intolerância, a violência, em detrimento da libertação, do conhecimento, da criticidade. As escolas sediadas no interior de nossos brasis, como a Escola Família Agrícola, precisam estar fortalecidas em suas bases e ideologias para que nenhuma influência externa dissolva o sonho de desenvolvimento no país dos esquecidos. Somos todos/todas/todes, iguais em deveres e direitos, portanto, nós que temos o privilégio de estudar em uma Universidade pública e somos conscientes da grande desigualdade social que assola nosso país, temos a obrigação de falar por e com essa população que sofre há séculos a desumanidade que favorece uns através do suor e do trabalho de outros. Com uma educação de qualidade que coloca os sujeitos em seus lugares de protagonismo, poderemos, pelo meno começar a dialogar de um jeito mais justo, mais igualitário.

\section{REFERÊNCIAS}

CARNEIRO, Maria José; CASTRO, Elisa Guaraná. Juventude rural em perspectiva/organizadoras: Maria José Carneiro, Elisa Guaraná de Castro. - Rio de Janeiro:Mauad X, 2011.

Escola "sem" partido : esfinge que ameaça a educação e a sociedade brasileira / organizador Gaudêncio Frigotto. Rio de Janeiro : UERJ, LPP, 2017. 
Silva, F. T. C. da; Maia, M. V. M.

FREIRE, Paulo . Educação como prática da liberdade . $18^{\mathrm{a}}$ Ed. Rio de Janeiro: Paz e Terra, 1987. 